\title{
Estudo de conforto em espaços abertos em região de clima temperado: o caso de Glasgow, Reino Unido
}

\author{
Outdoor comfort study in a region with temperate \\ climate: the case of Glasgow, UK
}

\section{Eduardo Leite Krüger \\ Patricia Regina Chaves Drach \\ Rohinton Emmanuel \\ Oscar Daniel Corbella}

\section{Resumo}

Eduardo Leite Krüger Programa de Pós-Graduação em Tecnologia Universidade Federal Tecnológica do Av. Sete de Setembro, 3165, Rebouças Curitiba - PR - Brasil CEP 80230-901

Tel.: (41) 3310-4725 Ramal 4725 E-mail: ekruger@utfpr.edu.br

Patricia Regina Chaves Drach Programa de Pós-Graduação em Urbanismo, Faculdade de Arquitetura e Urbanismo, Universidade Federal do Rio de J aneiro Av. Reitor Pedro Calmon, 500, Prédio da FAU, sala 521, Ilha do Fundão

Rio de J aneiro - RJ - Brasi CEP 21941-590

Tel.: (21) 2598-1990 Ramal 1978 E-mail: patricia.drach@gmail.com

Rohinton Emmanuel School of Engineering and Built Environment
Glasgow Caledonian University Glasgow - G4 OBA United Kingdom Tel.: 01413313217 E-mail: rohinton.emmanuel@gcu.ac.uk

Oscar Daniel Corbella Centro de Letras e Artes, Reitoria Universidade Federal do Rio de J aneiro Av. Reitor Pedro Calmon, 500, Ilha do Fundão

Rio de J aneiro - RJ - Brasi CEP 21941-590

Tel.: (21) 2598-1990 Ramal 1978 E-mail: oscar.corbella@gmail.com

Recebido em 08/09/11 Keywords: Urban climate. Urban planning. Thermal comfort indices. Outdoor Aceito em 01/12/11 thermal comfort. 


\section{Introdução}

A compreensão de fenômenos relacionados ao clima urbano, consequência de um processo generalizado de urbanização em diversas partes do mundo, pode e deve servir de subsídio para o planejamento urbano. De estudos elaborados nessa área, fatores controláveis pelo planejamento, como, por exemplo, taxa de permeabilidade do solo e distanciamento ótimo de prédios entre si, juntamente com restrições a sua altura, podem ser definidos de maneira científica e tecnicamente mais precisa, gerando ao mesmo tempo níveis mais elevados de conforto (interno e externo) e menor consumo de energia elétrica despendido em climatização ou iluminação artificial de edificações.

Nas mais recentes edições do Encontro Nacional de Conforto no Ambiente Construído (Encac) e eventos semelhantes (Passive and Low Energy Architecture - Plea, Passive and Low Energy Cooling for the Built Environment - Palenc), vemse notando a separação de temas voltados basicamente a duas vertentes distintas:

(a) conforto em ambientes internos, englobando as áreas de acústica, térmica e iluminação; e

(b) clima urbano, tratando de espaços externos.

Embora essa divisão inicial de tópicos de pesquisa pareça ser bastante clara e objetiva, diversos estudos deveriam levar em conta as inter-relações entre ambas as esferas. Fragmentam-se, na prática, o entendimento e a atuação do projetista para duas esferas, onde as questões são tratadas por profissionais distintos: pelo arquiteto e pelo urbanista. Conforme observa Emmanuel (2005), torna-se necessário expandir o conhecimento além das considerações climático-determinísticas de edificações isoladas e, ainda, segundo Givoni (1998), há por vezes uma interação complexa e mecanismos de retroalimentação entre as edificações e o clima exterior a elas. Se, por um lado, o ambiente interno é afetado pelas condições climáticas do entorno da edificação, por outro, a própria edificação e, especialmente, grupos de edificações modificam o clima local (ERELL; PEARLMUTTER; WILLIAMSON, 2011). Em condições de calor, Johansson (2006) cita ainda o fato de que os próprios equipamentos de climatização, enquanto resfriam o ar interno, emitem calor sensível ao entorno da edificação, criando uma retroalimentação positiva.

$\mathrm{Se}$, em regiões tropicais, verifica-se um processo contínuo de urbanização, em algumas cidades de países desenvolvidos, ocorre o processo inverso. $\mathrm{O}$ conceito de shrinking cities vem-se tornando uma realidade em diversas partes do mundo. Oswalt e
Rieniets (2007) relatam a queda populacional de 370 cidades industriais ao longo dos últimos 50 anos. Tanto em um caso (urbanização acelerada) como no outro (redução populacional e evasão), o desafio consiste na proposição de diretrizes para planejamento urbano climaticamente orientado considerando possíveis mudanças climáticas em um futuro próximo. Projeções de cenários para períodos definidos já são parte de planejamento estratégico, como o sugerido pelo UK Climate Impacts Programme (UKCIP).

O planejamento de cidades futuras (ou de novos empreendimentos urbanísticos) pode mitigar os efeitos globais relacionados às mudanças climáticas e até mesmo aliviar os impactos de grandes concentrações urbanas (geração de calor, poluentes, alterações nos padrões de vento e de precipitações, etc.), em uma retroalimentação negativa. Um exemplo da utilização de estratégias de planejamento urbano com implicações microclimáticas na recuperação de áreas urbanas degradadas é mostrado em um projeto recente de recuperação de um trecho de rio na zona urbana, em Seul, na Coreia do Sul. Recursos computacionais da área de climatologia urbana foram também utilizados, como a ferramenta de simulação de clima urbano, ENVI-met (BRUSE, 2009), para verificarem-se os impactos de alterações urbanas no microclima (HAN; MUN; HUH, 2007).

Contudo, ressalta-se a importância da definição de limites e condições microclimáticas ideais a serem almejadas em espaços externos. A partir de tais condições, o papel do planejamento seria utilizar recursos diversos (estratégias de sombreamento, inserção de praças e áreas de vegetação, adoção de fontes d'água, entre outros), de modo a se alterar de forma benéfica o microclima de espaços urbanos. Um desafio adicional é verificado de modo geral na área de climatologia urbana: o entendimento e a quantificação dos efeitos da morfologia urbana no microclima gerada por ela.

O presente trabalho faz parte de uma pesquisa mais abrangente, que envolve o estudo da ilha de calor e proposições para aumento da resiliência ou capacidade de adaptação da área urbana de Glasgow, Reino Unido, quanto a mudanças climáticas, uma cidade com esvaziamento populacional (shrinking city), localizada em região temperada. Neste artigo, apresentam-se resultados de uma pesquisa de campo realizada em ruas de pedestres de Glasgow, conduzida por meio de entrevistas estruturadas (questionário baseado na norma internacional ISO 10551 (INTERNATIONAL..., 1995)) a partir de uma

8 Krüger, E. L.; Drach, P. R. C.; Emmanuel, R.; Corbella, O. D. 
amostra de 763 pessoas, concomitantemente à medição de variáveis climáticas. Com o objetivo de identificar os índices e variáveis climáticas mais relevantes para a sensação térmica real, apresentase inicialmente uma comparação entre sensação térmica, conforme relatada pelos transeuntes entrevistados, e índices utilizados pela Meteorologia (Wind Chill e Temperature Humidity Sun Wind - THSW) e em estudos de conforto (Predicted Mean Vote - PMV e Physiological Equivalent Temperature - PET), estes últimos obtidos no pós-processamento dos dados a partir do UC Berkeley Thermal Comfort Program "WinComf" versão batch 1.01 (FOUNTAIN; HUIZENGA, 1997), e com a ferramenta Rayman, versão 2.0 (MATZARAKIS; RUTZ, 2010) respectivamente. Complementarmente, discute-se a importância relativa de variáveis climáticas, medidas na sensação térmica a partir de uma equação de regressão linear múltipla (software Statistica), gerada a partir da série de dados coletada. A adoção de tal equação para o presente estudo foi baseada em procedimento utilizado no projeto da União Europeia Ruros - Rediscovering the Urban Realm and Open Spaces (NIKOLOPOULOU, 2004a), para sete cidades europeias, relacionando votos de sensação térmica (ASV ou actual sensation vote) a variáveis climáticas monitoradas in loco. $\mathrm{O}$ mesmo procedimento foi adotado anteriormente, a partir de uma base de dados coletada em Curitiba, PR, por um dos autores (KRÜGER; GIVONI; ROSSI, 2010).

\section{Índices térmicos utilizados}

O conhecimento das faixas ideais de temperatura, irradiação solar global, velocidade do ar, umidade do ar, enfim, das condições de menor desconforto térmico externo, deveria ser o ponto de partida para qualquer tentativa de intervenção nos espaços abertos através do desenho urbano. Como a sensação térmica depende de diversos fatores, em geral se adota algum índice térmico para expressála (COMFA, ITS, OUT_SET*, PET, UTCI, entre outros). Em outros casos, alguma variável de interesse, em geral a temperatura do ar, é adotada na determinação de condições térmicas ideais no espaço aberto. Conforme Erell, Pearlmutter e Williamson (2011, p. 135), o conceito de aceitabilidade térmica é de fundamental importância para o desenho urbano, estabelecendo as condições climáticas que deveriam ser almejadas por um bom planejamento.

Para o cálculo dos índices térmicos avaliados foram selecionados dois softwares. O UC Berkeley Thermal Comfort Program "WinComf" fornece como dados de saída a predição de conforto pelos índices PMV, ET*, SET*. O WinComf versão 1.01 (1994-1995) foi desenvolvido para a American Society of Heating, Refrigeration, and Air-Conditioning Engineers (ASHRAE), e sua versão "batch" possibilita leitura do arquivo de entrada através de um banco de dados. Utilizou-se o WinComf para a determinação do Predicted Mean Vote (PMV), índice baseado em estados permanentes de transferência de calor e desenvolvido para ambientes internos, sendo utilizado na ISO $7730^{1}$ (INTERNATIONAL..., 2005).

O software Rayman versão 2.0 (MATZARAKIS; RUTZ, 2010) fornece três índices de conforto térmico, sendo um deles a temperatura fisiológica equivalente (Physiological Equivalent Temperature - PET), baseado no MEMI (Munich Energy-balance Model for Individuals) e expresso em graus Celsius. Höppe (1999) define o PET como a temperatura fisiológica equivalente, em determinado ambiente (interno ou externo), à temperatura do ar de um ambiente interno de referência, no qual o balanço térmico humano é mantido com temperatura da pele e do centro do corpo iguais àquelas das condições em avaliação. O PET é um dos métodos recomendados pela regulamentação alemã para planejamento urbano e regional (ASSOCIATION..., 1998) e é adotado para predição de mudanças na componente térmica de climas urbanos e regionais (HONJO, 2009).

Entre os índices utilizados pela Meteorologia e adotados nesta pesquisa, o Wind Chill Factor, calculado pelo software WeatherLink, usado para baixar os dados coletados pela estação Davis, leva em conta o efeito do vento na percepção da temperatura ambiente. $O$ índice é diretamente proporcional à velocidade do ar, porém se restringe a temperaturas do ar inferiores a $10{ }^{\circ} \mathrm{C}$ e a velocidades do ar acima de 4,8 km/h $(1,33 \mathrm{~m} / \mathrm{s})$. No WeatherLink, o Wind Chill é calculado de acordo com a equação dada por Osczevski (1995), segundo método utilizado pelo US National Weather Service.

Também fornecido pelo WeatherLink, o índice térmico Temperature Humidity Sun Wind (THSW) combina os fatores de umidade e temperatura do ar, considerando os efeitos de resfriamento da velocidade do ar e dos ganhos térmicos por radiação solar direta, usando o conceito de

\footnotetext{
${ }^{1}$ Embora o Rayman forneça resultados em termos de PMV, foram observadas discrepâncias nas saídas em PMV de ambos os softwares, e os resultados do Rayman divergiam até mesmo dos exemplos apresentados na ISO 7730 (Tabela D. 1, ISO 7730). Por fim, adotou-se o valor obtido do PMV para a série de dados a partir do WinComf, pois esse software foi desenvolvido especificamente para a ASHRAE, que incorpora o método do PMV em avaliações de desempenho.
} 
temperatura aparente, conforme definido por Steadman (1984).

\section{Área de estudo}

De acordo com a classificação de Koeppen-Geiger, a região em torno de Glasgow $\left(55^{\circ} 51^{\prime} \mathrm{N}, 04^{\circ} 12^{\prime} \mathrm{W}\right)$ é caracterizada por um clima temperado $(\mathrm{Cfb})$, suavizado pela influência marítima. Tal influência afeta principalmente a variação térmica sazonal. O nível de precipitação é um dos mais altos no Reino Unido (precipitação anual de $1.100 \mathrm{~mm}$ ). A temperatura média máxima nos meses mais quentes do ano (julho e agosto) situa-se abaixo de $20{ }^{\circ} \mathrm{C}$, e pelo menos durante cinco meses do ano a média diária fica acima de $10{ }^{\circ} \mathrm{C}$ (UK MET OFFICE, 2011).

A área estudada na presente pesquisa consiste na zona de pedestres do centro da cidade de Glasgow, que se estende por cerca de $1,5 \mathrm{~km}$ entre a Argyle Street e a Sauchiehall Street, cobrindo a rua principal, a Buchanan Street, na forma de um " $Z$ " (Figura 1).

Dentro desse trecho, foram selecionadas situações para a coleta de respostas de sensação e preferência térmica de passantes que representassem condições urbanas diferenciadas quanto aos seguintes fatores:

(a) orientação do eixo da via;

(b) abertura para o céu (fator de visão do céu); e

(c) situação em cânion e fora dele (cruzamento e praça).

Os pontos escolhidos para a coleta de dados são apresentados no Quadro 1, com um breve descritivo de suas características urbanas. Como informação adicional, apresenta-se a imagem obtida a partir de lente olho de peixe em cada local, juntamente com o valor do fator de visão do céu (FVC), adotado como indicador da forma urbana em cada ponto ${ }^{2}$.

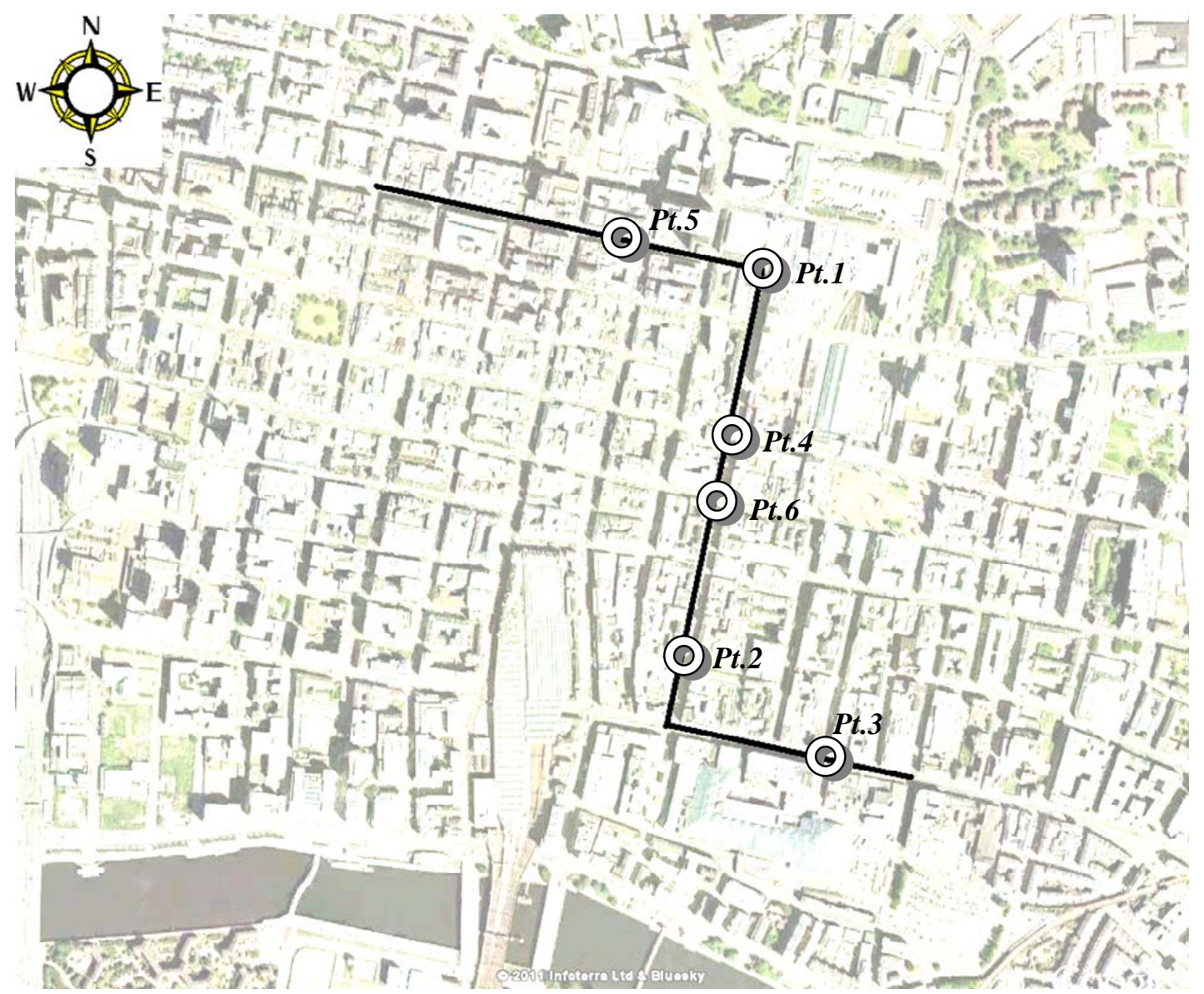

Figura 1 - Trecho da zona de pedestres analisado no centro de Glasgow, com localização dos pontos de monitoramento

${ }^{2}$ Obtidos a partir de fotos tiradas com lente FC-E8 acoplada a uma câmera Nikon CoolPix 4500. A câmera foi posicionada em cada local
medido, à mesma altura dos sensores de temperatura do ar e umidade relativa. Na sequência, utilizou-se o programa RayMan para o medido, à mesmalo do FVC

10 Krüger, E. L.; Drach, P. R. C.; Emmanuel, R.; Corbella, O. D. 
Quadro 1 - Localização e descrição dos pontos de monitoramento

\begin{tabular}{|c|c|c|c|}
\hline Ponto & Código & Localização e descrição & $\begin{array}{c}\text { Imagem com lente olho } \\
\text { de peixe }\end{array}$ \\
\hline 1 & CS-1,6,12,19 & $\begin{array}{l}\text { Esquina entre Buchanan Street } \\
\text { e Sauchiehall Street, em frente } \\
\text { ao Royal Concert Hall - } \\
\text { cruzamento entre as duas vias, } \\
\text { trecho bem adensado, com } \\
\text { canalização de ar pela via }\end{array}$ & \\
\hline 2 & CS-2,7,14 & $\begin{array}{l}\text { Trecho mais ao sul da } \\
\text { Buchanan Street - situação de } \\
\text { cânion urbano com prédios } \\
\text { regulares em ambos os lados } \\
\text { da via }\end{array}$ & \\
\hline 3 & CS-3,13,18 & $\begin{array}{l}\text { Cruzamento da Argyle Street } \\
\text { com a Miller Street - trecho } \\
\text { relativamente aberto, com boa } \\
\text { circulação de ar }\end{array}$ & \\
\hline 4 & CS-4,9,15 & $\begin{array}{l}\text { Nelson Mandela Place - } \\
\text { situação de praça urbana com } \\
\text { via motorizada ao redor (West } \\
\text { George Street) }\end{array}$ & \\
\hline 5 & CS-5,10,17 & $\begin{array}{l}\text { Sauchiehall Street - situação } \\
\text { de cânion urbano com prédios } \\
\text { regulares em ambos os lados } \\
\text { da via }\end{array}$ & \\
\hline 6 & CS-8,11,16 & $\begin{array}{l}\text { Ponto localizado na metade do } \\
\text { trecho de pedestres da } \\
\text { Buchanan Street - situação de } \\
\text { cruzamento de rua de } \\
\text { pedestres e via motorizada (St. } \\
\text { Vincent Street) }\end{array}$ & \\
\hline
\end{tabular}




\section{Instrumentação e método adotado para coleta de dados}

Para a coleta de dados foi utilizada uma estação meteorológica Davis Vantage Pro2 (Figura 2), equipamento wireless composto de duas partes: conjunto de sensores e console digital (data logger) usado para armazenamento de dados. O conjunto de sensores é composto de: sensor de temperatura e umidade do ar; anemômetro de copo com pá de vento; piranômetro de silício; e coletor de água de chuva. Adicionalmente, montou-se uma esfera de PVC, pintada na cor cinza (primer), na qual se inseriu um medidor de temperatura (Tinytag TGP-4500), com diâmetro aproximado de
$110 \mathrm{~mm}$. Os sensores de temperatura do ar e umidade relativa, assim como o termômetro de globo, foram fixados à altura de $110 \mathrm{~cm}$, conforme $\begin{array}{llll}\text { recomendações da } & \text { ISO } & 7726\end{array}$ (INTERNATIONAL..., 1998). O piranômetro foi fixado a $140 \mathrm{~cm}$, e o anemômetro, a $150 \mathrm{~cm}$, de modo que os dados coletados estivessem o mais próximo possível do nível do pedestre/entrevistado. A grande vantagem da estação utilizada foi o baixo peso do conjunto (tripé/estação), aproximadamente $7 \mathrm{~kg}$, o que facilitou enormemente o transporte a pé para cada campanha realizada. As características de cada sensor usado estão indicadas na Tabela 1.

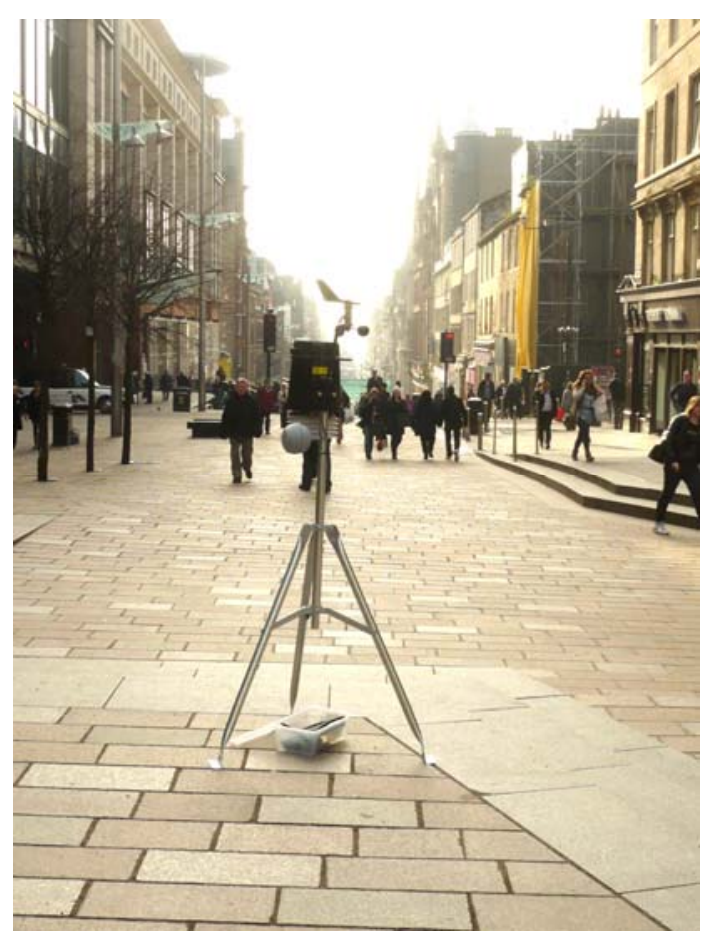

Figura 2 - Estação meteorológica Davis Vantage Pro2 com termômetro de globo cinza, no ponto CS-1

Tabela 1 - Características do equipamento usado para as medições

\begin{tabular}{|c|c|c|c|}
\hline Sensor & $\begin{array}{c}\text { Resolução por unidade } \\
\text { de medida }\end{array}$ & Intervalo de medição & Precisão \\
\hline Temperatura do ar & $\begin{array}{c}0,1^{\circ} \mathrm{C} \text { ou } 1{ }^{\circ} \mathrm{C} \text { (user- } \\
\text { selectable) }\end{array}$ & $-40{ }^{\circ} \mathrm{Ca}+65^{\circ} \mathrm{C}$ & $\begin{array}{c} \pm 0,5^{\circ} \mathrm{C} \text { acima de } 20^{\circ} \mathrm{F}(-7 \\
\left.{ }^{\circ} \mathrm{C}\right)\end{array}$ \\
\hline Umidade do ar & $1 \%$ & $1 \%$ a $100 \%$ & $\begin{array}{c} \pm 3 \%(0-90 \%), \pm 4 \%(90- \\
100 \%)\end{array}$ \\
\hline Velocidade do ar & $0,4 \mathrm{~m} / \mathrm{s}$ & $1 \mathrm{a} 80 \mathrm{~m} / \mathrm{s}$ & $\pm 1 \mathrm{~m} / \mathrm{s}$ \\
\hline Direção do vento & $22,5^{\circ}$ & $0-360^{\circ}$ & $\pm 3^{\circ}$ \\
\hline Radiação solar & $1 \mathrm{~W} / \mathrm{m} 2$ & 0 a $1.800 \mathrm{~W} / \mathrm{m} 2$ & $\pm 5 \%$ \\
\hline $\begin{array}{l}\text { Temperatura do ar } \\
\text { (Tinytag TGP-4500) }\end{array}$ & $0,01{ }^{\circ} \mathrm{C}$ & $-25^{\circ} \mathrm{C} \mathrm{a}+85^{\circ} \mathrm{C}$ & $\pm 0,45^{\circ} \mathrm{C}$ \\
\hline
\end{tabular}

12 Krüger, E. L.; Drach, P. R. C.; Emmanuel, R.; Corbella, O. D. 
O monitoramento das variáveis microclimáticas foi realizado no período diurno, durante 19 campanhas de três horas de medição com aplicação simultânea de questionários de sensação e preferência térmica. Para obter-se a temperatura radiante média (TRM) a partir dos dados de temperatura coletados pelo sensor encapsulado (com a emissividade da esfera de PVC cinza assumida como 0,95) e da velocidade do ar no momento da medição, foi utilizada a equação para convecção forçada, constante da ISO 7726 (INTERNATIONAL..., 1998). Os dados climáticos foram gravados de $5 \mathrm{~s}$ em 5 s. Para que fossem obtidos resultados mais precisos, foi calculada uma média de todos os segundos, para composição do minuto.

As variáveis pessoais e de sensação térmica foram obtidas por meio de questionários, desenvolvidos com base na norma internacional ISO 10551 (INTERNATIONAL..., 1995). As variáveis pessoais levantadas foram sexo, idade, altura, peso, tempo de residência na cidade (fator aclimatação) e vestimenta (adotou-se a tabela resumo de trajes típicos, conforme apresentada no Anexo A da ISO 9920 (INTERNATIONAL..., 2007), Tabela A.1, para estimativa do coeficiente de isolamento térmico da vestimenta, dado em "clo"), além das variáveis sobre percepção térmica (sensação e preferência), para as quais se utilizou escala simétrica de 7 pontos. No caso da sensação térmica (How do you feel at this precise moment?), as respostas foram categorizadas em:
(a) (-3) cold;
(b) (-2) cool;
(c) (-1) slightly cool;
(d) (0) neutral;
(e) (+1) slightly warm;
(f) (+2) warm; e
(g) $(+3)$ hot.

Em relação à preferência térmica (Please state how you would prefer to be now), as respostas foram:
(a) (+3) much warmer;
(b) (+2) warmer;
(c) (+1) a little warmer;
(d) (0) neither warmer nor cooler;
(e) (-1) a little cooler;
(f) (-2) cooler; e
(g) (-3) much cooler.

Para a taxa metabólica, assumiu-se um valor fixo de 2,8 met (pessoa caminhando a uma velocidade de $4 \mathrm{~km} / \mathrm{h}^{3}$, situação típica no caso de passantes). $\mathrm{O}$ tempo de residência foi adotado como critério de exclusão, quando inferior a seis meses. Uma questão crucial avaliada refere-se ao tempo de permanência no espaço aberto (time spent outdoors, em minutos), a qual é discutida na seção seguinte.

\section{Amostra obtida}

A amostra obtida é composta de $763^{4}$ votos de sensação/preferência térmica. As campanhas de medição estenderam-se durante três estações do ano (inverno, primavera e verão), em geral em dias ensolarados ou com ausência de chuva. Devido à instabilidade dessas condições nos períodos de inverno e primavera, a maior concentração dos dados ocorre no período de verão.

Excetuando-se 27 respostas, relativas a casos exceção (não residentes, grávidas, trabalhadores braçais), permanece um total de 736 pessoas. Uma exclusão adicional daqueles que se encontravam no ambiente externo há menos de $15 \mathrm{~min}$ é proposta mais adiante. Um cuidado adicional foi o de buscar-se um equilíbrio na quantidade de respondentes por cada ponto analisado. Embora os pontos de monitoramento não se distanciem sobremaneira (o trecho completo tem cerca de 1,5 $\mathrm{km}$ de extensão), notaram-se diferenças visíveis (sociais e culturais) nos frequentadores de cada ponto; além desse fato, devem ser considerados fatores psicológicos e de contexto no entorno de cada ponto, que, embora possam ser desconsiderados em espaços internos edificados, possuem relevância em espaços abertos, conforme sugerido por Nikolopoulou e Steemers (2003) e Spagnolo e de Dear (2003).

De modo a neutralizarem-se tais efeitos, procurouse distribuir uniformemente a quantidade de entrevistados por ponto. A tabela seguinte (Tabela 2) apresenta o número de entrevistados por ponto monitorado, com os dias do ano referentes a cada campanha. Assumindo como distribuição ideal para as 6 localidades escolhidas cerca de $17 \%$ do total de respostas (com 3 visitas a cada ponto), a discrepância em termos da quantidade de respondentes por ponto foi relativamente pequena, variando entre 100 e 143 pessoas por ponto para

\footnotetext{
${ }^{3}$ Segundo a norma internacional ISO 7730 (INTERNATIONAL..., 2005), Tabela B. 1

${ }^{4}$ Acerca do tamanho da amostra, Glasgow possui atualmente cerca de 600 mil habitantes (Decennial Census records at the National Records of Scotland). Para definição do tamanho da amostra para este estudo, considerou-se uma margem de erro de $5 \%$ nível de confiança de $95 \%$ e uma distribuição de resposta de $33 \%$ (conforto, desconforto por frio ou desconforto por calor, em graus diversos - escala de 7 pontos), o que resulta em uma quantidade total mínima em torno de 350 pessoas.
} 
toda a série, e de 79 a 114 pessoas por ponto para a amostra composta de transeuntes com pelo menos 15 min de exposição (15 min+).

O tempo de permanência mínimo no ambiente exterior para estudos de conforto em espaços abertos é bastante controverso. Utilizando o modelo Imem (Instationary Munich Energy-Based Model), Höppe (2002) enfatiza que o tempo de "aclimatação" de um indivíduo, em situação de inverno, saindo de um ambiente aclimatizado para condições externas, corresponde a atingir o período estacionário de trocas de calor entre a superfície da pele e o meio, o que ocorre apenas após algumas horas. Höppe apresenta a partir daí sua crítica quanto ao uso de modelos de conforto baseados em regime estacionário em espaços abertos. Uma vez que a quantidade de indivíduos com exposição prolongada em condições de inverno seria extremamente restrita, particularmente tratando-se de passantes (voluntários), usuários do espaço aberto, definiram-se 15 minutos de exposição como o tempo mínimo de permanência para cada entrevistado. Tal limite de tempo refere-se ao mínimo recomendado pela ANSI/ASHRAE 55 (AMERICAN..., 2004) para estudos de conforto em espaços internos.

A amostra encontrada (15 $\mathrm{min}+$ ) consiste de 568 indivíduos, com $61 \%$ dos entrevistados do sexo masculino e $39 \%$ do sexo feminino, com idade variando entre 12 e 86 anos.

Quanto às variações climáticas encontradas para os diversos dias de medição, a Tabela 3 apresenta as faixas de variação das variáveis monitoradas.

Dos dados obtidos, foi gerada uma equação de regressão múltipla (Statistica, versão 8.0), na qual a sensação térmica - ST foi mantida como variável dependente e os diversos fatores climáticos (temperatura do ar - $\mathrm{T}$, umidade relativa - UR, velocidade do ar - v, irradiância solar global e refletida - Ig, temperatura radiante média - TRM) foram adotados como variáveis independentes. A equação obtida com todas as variáveis climáticas é dada por (Equação 1):

$\mathrm{ST}=-3,54841+0,17516 * \mathrm{~T}+0,01148 * \mathrm{UR}-$ $0,28435^{*} \mathrm{v}+0,00047 * \operatorname{Ig}+0,01647 * \mathrm{TRM}$

Eq. 1

Tabela 2 - Dias de monitoramento e distribuição de votos por ponto

\begin{tabular}{|c|c|c|c|c|c|}
\hline Ponto & Dias monitorados & $\begin{array}{c}\text { Quantidade de } \\
\text { respondentes }\end{array}$ & $\%$ & $\begin{array}{c}\text { Quantidade de } \\
\text { respondentes (15 } \mathrm{min}+)\end{array}$ & $\%$ \\
\hline 1 & $\begin{array}{l}\text { Campanha 1: 3/03/2011, 12h00-15h00 } \\
\text { Campanha 6: } 17 / 05 / 2011,10 \mathrm{~h} 00-13 \mathrm{~h} 00 \\
\text { Campanha 12: 7/07/2011, 10h00-13h00 } \\
\text { Campanha 19: } 29 / 07 / 2011,10 \mathrm{~h} 35-13 \mathrm{~h} 35\end{array}$ & 131 & 18 & 93 & 16 \\
\hline 2 & $\begin{array}{l}\text { Campanha 2: } 17 / 03 / 2011,10 \mathrm{~h} 45-13 \mathrm{~h} 45 \\
\text { Campanha } 7: 02 / 06 / 2011,10 \mathrm{~h} 00-13 \mathrm{~h} 00 \\
\text { Campanha 14: } 14 / 07 / 2011,10 \mathrm{~h} 15-13 \mathrm{~h} 15\end{array}$ & 100 & 14 & 79 & 14 \\
\hline 3 & $\begin{array}{l}\text { Campanha } 3: 24 / 03 / 2011,10 \mathrm{~h} 00-13 \mathrm{~h} 00 \\
\text { Campanha } 13: 12 / 07 / 2011,10 \mathrm{~h} 15-13 \mathrm{~h} 15 \\
\text { Campanha } 18: 27 / 07 / 2011,10 \mathrm{~h} 15-13 \mathrm{~h} 15\end{array}$ & 143 & 19 & 114 & 20 \\
\hline 4 & $\begin{array}{l}\text { Campanha 4: 4/05/2011, 10h00-13h00 } \\
\text { Campanha 9: 15/06/2011, 10h00-13h00 } \\
\text { Campanha 15: 21/07/2011, 10h15-13h15 }\end{array}$ & 132 & 18 & 102 & 18 \\
\hline 5 & $\begin{array}{l}\text { Campanha 5: 11/05/2011, 10h00-13h00 } \\
\text { Campanha 10: 23/06/2011, 10h00-13h00 } \\
\text { Campanha 17: 25/07/2011, 10h15-13h15 }\end{array}$ & 118 & 16 & 94 & 17 \\
\hline 6 & $\begin{array}{l}\text { Campanha } 8: 9 / 06 / 2011,10 \mathrm{~h} 00-13 \mathrm{~h} 00 \\
\text { Campanha } 11: 28 / 06 / 2011,10 \mathrm{~h} 00-13 \mathrm{~h} 00 \\
\text { Campanha } 16: 22 / 07 / 2011,10 \mathrm{~h} 00-13 \mathrm{~h} 00\end{array}$ & 112 & 15 & 86 & 15 \\
\hline
\end{tabular}

Tabela 4 - Faixas de variação dos dias monitorados

\begin{tabular}{|c|c|c|c|c|c|c|}
\hline & $\begin{array}{c}\text { Temperatur } \\
\text { a do ar (Ta } \\
\left.\text { em }^{\circ} \mathrm{C}\right)\end{array}$ & $\begin{array}{c}\text { Umidade } \\
\text { relativa } \\
\text { (UR em } \\
\% \text { ) }\end{array}$ & $\begin{array}{c}\text { Velocidade } \\
\text { do ar (v em } \\
\text { m/s) }\end{array}$ & $\begin{array}{l}\text { Irradiância } \\
\text { solar global e } \\
\text { refletida (Ig } \\
\text { em W/m2) }\end{array}$ & $\begin{array}{c}\text { Temperatura } \\
\text { do globo cinza } \\
\left(\mathrm{Tg} \mathrm{em}^{\circ} \mathrm{C}\right)\end{array}$ & $\begin{array}{l}\text { Temperatura } \\
\text { radiante } \\
\text { média (TRM } \\
\left.\text { em }{ }^{\circ} \mathrm{C}\right)\end{array}$ \\
\hline $\begin{array}{l}\text { Faixa de } \\
\text { variação }\end{array}$ & $7,9-21,9$ & $28-77$ & $0-3,6$ & $42-1.095$ & $9,0-28,8$ & $9,0-49,1$ \\
\hline
\end{tabular}

14 Krüger, E. L.; Drach, P. R. C.; Emmanuel, R.; Corbella, O. D. 
A equação de regressão apresenta $\mathrm{R}=0,47$, $R^{2}=0,22$, com $p<0,0000$ e um erro de estimativa de 1,2154 para a sensação térmica. Como dois termos da Eq. 1 não são estatisticamente significativos (TRM, com $\mathrm{p}=0,211762$, e UR, com $\mathrm{p}=0,090750$ ), decidiu-se por removê-los da equação original, mantendo-se Ig $(\mathrm{p}=0,114507)$, por ser notadamente variável de influência na percepção térmica humana. A equação de regressão resultante, com coeficientes de correlação e determinação inalterados, é dada por (Equação 2):

$\mathrm{ST}=-2,83839+0,19248 * \mathrm{~T}-0,19616 * \mathrm{v}+0,00050 * \mathrm{Ig}$

Eq. 2

Embora o valor do coeficiente de correlação encontrado tenha sido relativamente baixo, está de acordo com o que em geral se obtém em estudos em espaços abertos. Para o continente europeu, estudos conduzidos no escopo do projeto Ruros, mencionado anteriormente, apresentaram $\mathrm{R}$ variando entre 0,27 e 0,68 (NIKOLOPOULOU, 2004b). A baixa correlação é um reflexo da grande variação de respostas para semelhantes condições climáticas de exposição, o que mostra o aspecto subjetivo desse tipo de estudo, demandando amostras de tamanho significativo. Alerta-se que, uma vez que há diferenças em termos de variáveis pessoais (sexo, idade, altura, peso, vestimenta), tais fatores são de influência na estimativa da sensação de conforto. Contudo, como se pretende analisar os efeitos do microclima apenas, estes não foram adotados como variáveis independentes na equação de regressão.

\section{Resultados encontrados}

São apresentados inicialmente efeitos observados em grupos de variáveis, verificando a consistência da base de dados obtida comparativamente à literatura. Em seguida, foram comparadas as respostas dos entrevistados em termos de sensação térmica (na escala de -3 a +3 ) a resultados numéricos expressos em Wind Chill, THSW, PMV e PET. Como última etapa de análise, avaliou-se o efeito isolado de variáveis climáticas na sensação de conforto, a partir da equação múltipla derivada a partir dos dados coletados (Eq. 2).

\section{Análise de grupos}

Utiliza-se para tais análises a comparação de dados de sensação térmica a partir das entrevistas versus resultados obtidos a partir da equação de regressão para sensação térmica estimada ST (Eq. 1). A diferença das respostas obtidas para determinado grupo ao valor esperado para a amostra como um todo representa a sensibilidade térmica relativa desse grupo (KRÜGER; GIVONI; ROSSI, 2010). Agrupou-se a amostra segundo as categorias de sexo, idade e índice de massa corporal (IMC).

A figura abaixo (Figura 3) representa a comparação de entrevistados de ambos os sexos quanto a sua sensação térmica (declarada) relativamente ao valor esperado de ST. Percebe-se que a amostra feminina apresenta maior sensibilidade ao frio que ao calor, igualando-se a dos homens apenas quando ST aproxima-se de 1,5.

O agrupamento dos indivíduos segundo faixa etária (Figura 4) baseou-se na classificação da Organização Mundial de Saúde (WORLD..., 1995):

(a) abaixo de 25 anos (jovens);

(b) entre 25 e 64 (adultos); e

(c) acima de 64 (idosos).

Verifica-se que, embora ST para a condição de conforto (valor 0) seja coincidente para os três casos, a sensibilidade das pessoas mais idosas é maior tanto para frio quanto para calor. 


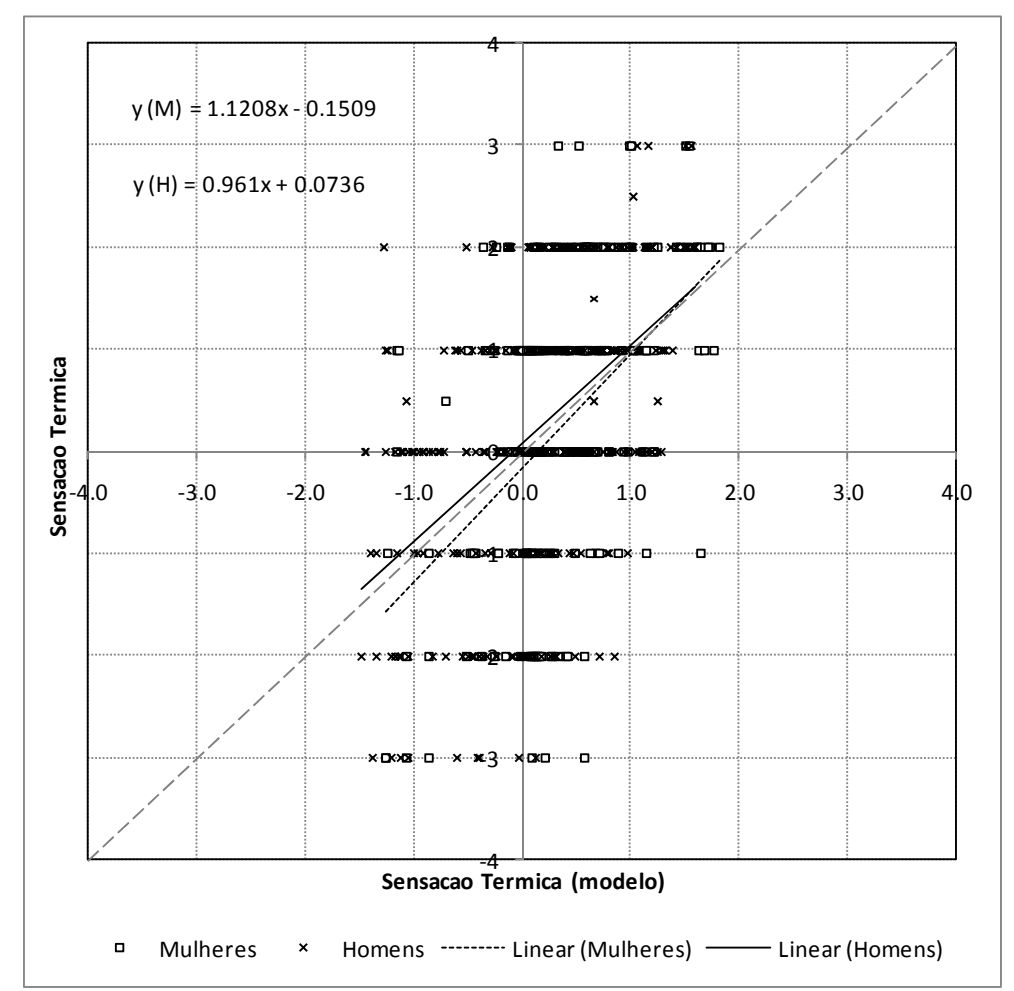

Figura 3 - Diferenças na sensação térmica (predita e observada) quanto ao aspecto sexo

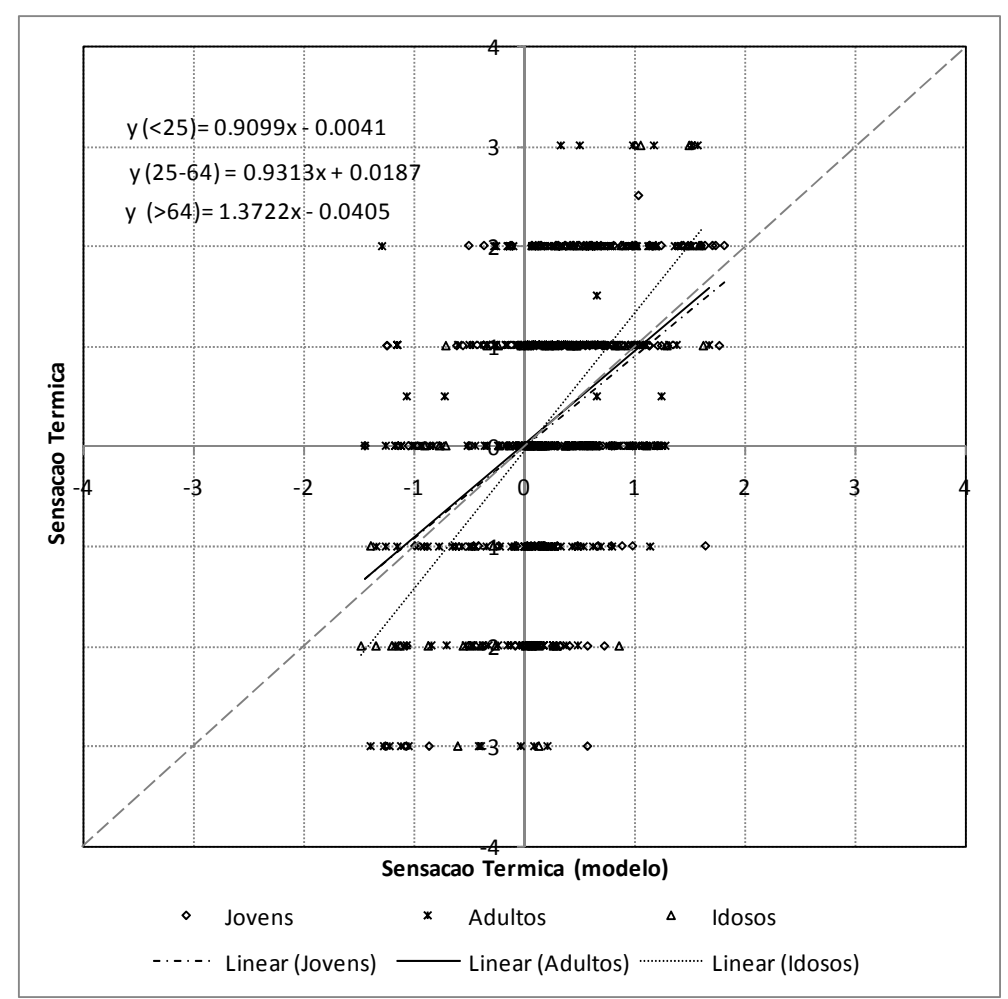

Figura 4 - Diferenças na sensação térmica (predita e observada) quanto ao aspecto faixa etária 


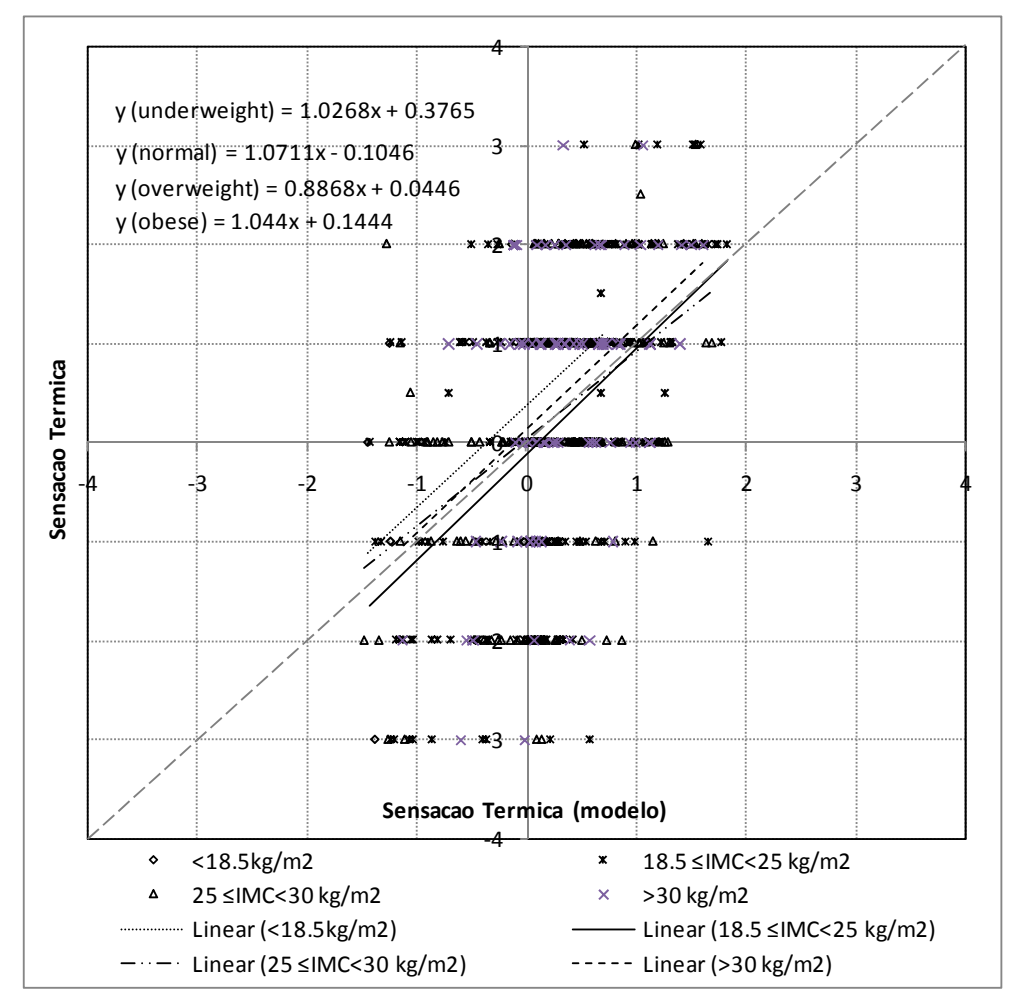

Figura 5 - Diferenças na sensação térmica (predita e observada) quanto ao aspecto IMC

Por fim, utilizou-se o critério índice de massa corporal (IMC) (Figura 5), conforme obtido pela expressão IMC $=$ peso/(altura $)^{2}$, com peso dado em quilogramas e altura em metros. Os dados de IMC foram agrupados segundo a OMS (WORLD..., 1995) nas classes:

(a) abaixo do peso (IMC $<18,5 \mathrm{~kg} / \mathrm{m}^{2}$ ), participando com 3,5\% do total de entrevistados;

(b) normal $\left(18,5 \leq \mathrm{IMC}<25 \mathrm{~kg} / \mathrm{m}^{2}\right), 48,6 \%$ do total;

(c) acima do peso $\left(25 \leq \mathrm{IMC}<30 \mathrm{~kg} / \mathrm{m}^{2}\right), 33,5 \%$; e

(d) obeso (acima de $30 \mathrm{~kg} / \mathrm{m}^{2}$ ), 14,4\%.

\section{Comparação com índices térmicos}

A comparação de índices utilizados pela Meteorologia, no caso, o Wind Chill e o THSW, conforme gerados pelo software WeatherLink para cada momento de entrevista, versus dados de sensação térmica é apresentada nas figuras abaixo. Como o Wind Chill restringe-se mais a condições de frio, a aplicação desse índice foi limitada aos períodos em que o valor obtido era inferior à temperatura ambiente ( $6 \%$ dos casos). O THSW, índice térmico mais relacionado ao calor, foi considerado para situações em que o valor obtido era superior à temperatura ambiente $(81 \%$ dos casos).
A aplicabilidade de ambos os índices foi verificada extraindo-se dados médios de sensação térmica para uma faixa de variação de um grau em cada escala (Wind Chill e THSW), conforme o método de agrupamento sugerido por de Dear e Fountain (1994). Para o primeiro índice, a correlação entre os resultados encontrados e a média das respostas de sensação térmica foi praticamente inexistente e, considerando a base de dados extremamente limitada ( $6 \%$ do total), o Wind Chill mostra pouca aplicabilidade como possível indicador da sensação térmica (Figura 6). Contudo, para o THSW (Figura 7), a correlação foi significativa, sugerindo que tal índice possa ser utilizado, para as condições locais, como bom indicador da sensação térmica. Nesse caso, a equação de regressão (para a amostra de $81 \%$ do total dos dados coletados) é dada pela Equação 3:

$\mathrm{ST}=0,1638 * \mathrm{THSW}-1,4499$

Eq. 3

Substituindo $\mathrm{ST}=0$, tem-se a temperatura neutra (em termos de THSW) para a amostra, de $8,9^{\circ} \mathrm{C}$.

A etapa seguinte envolveu a comparação dos índices de conforto PET e PMV com os dados de sensação térmica obtidos a partir das respostas dos questionários. Novamente, avaliou-se a aplicabilidade de ambos os índices extraindo-se dados médios de sensação térmica para uma faixa de variação de um grau na escala de PET e de uma casa decimal na escala do PMV. 


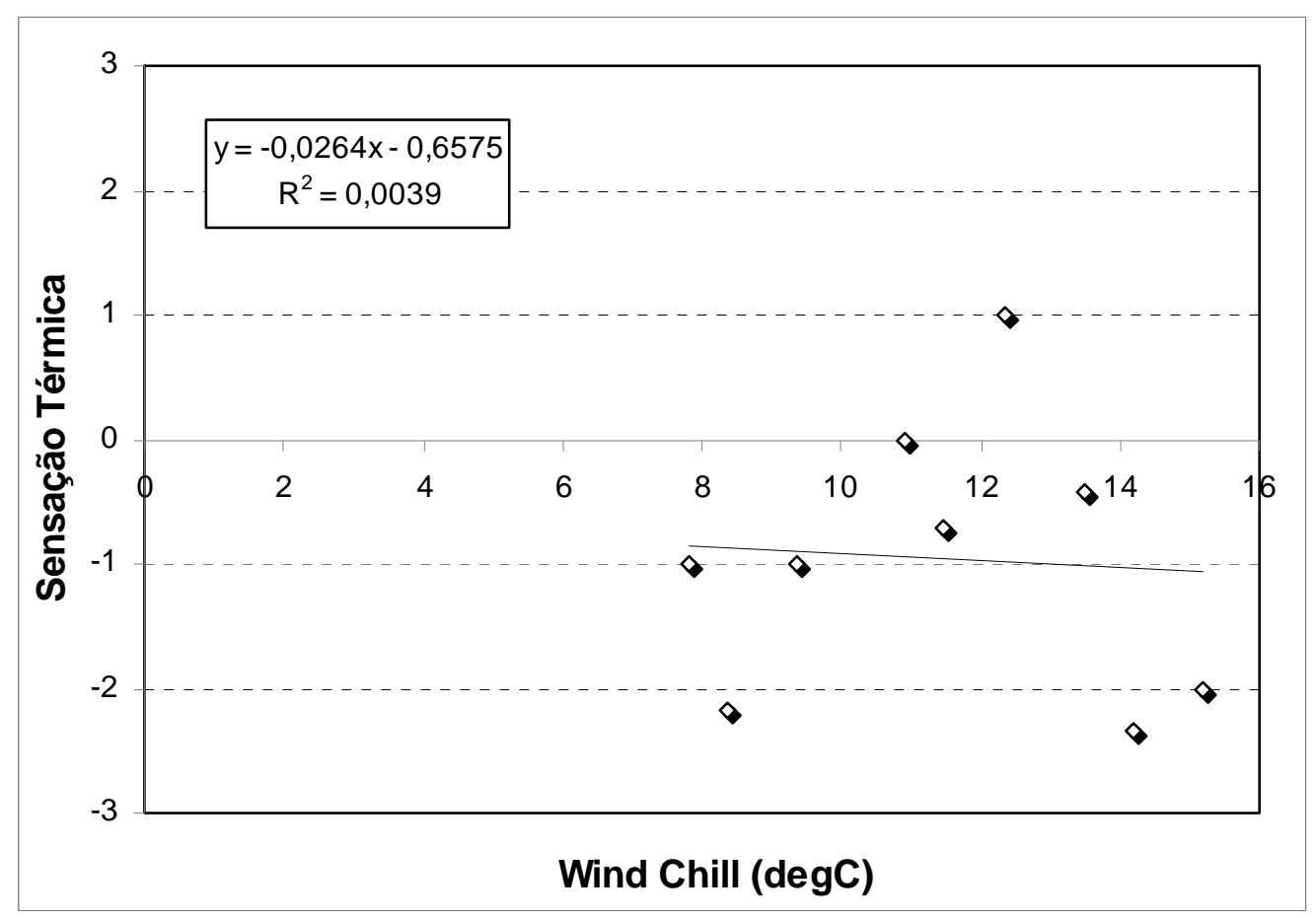

Figura 6 - Sensação térmica média versus Wind Chill (valores agrupados por faixas de 1 grau da escala de Wind Chill)

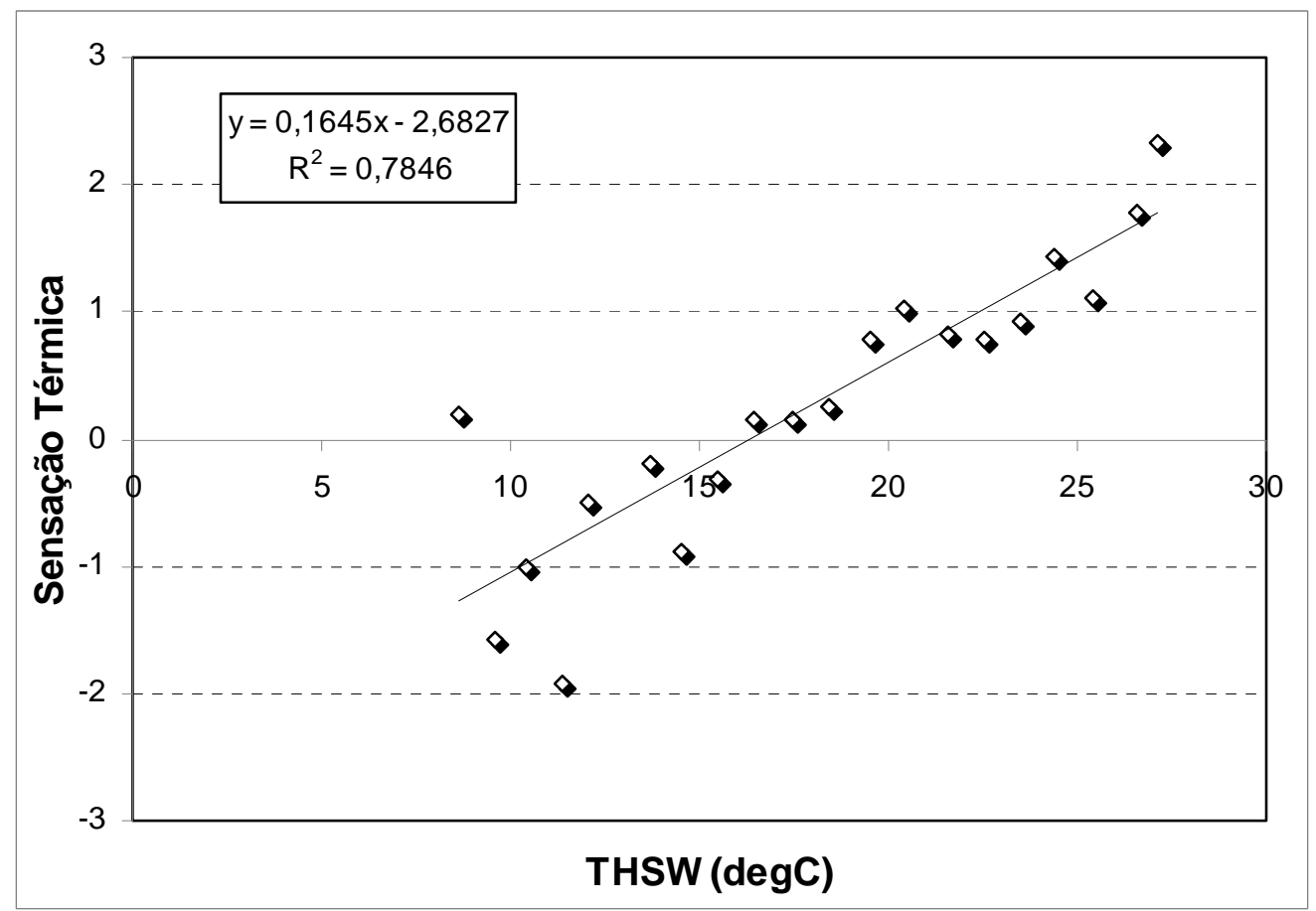

Figura 7 - Sensação térmica média versus THSW (valores agrupados por faixas de 1 grau da escala de THSW)

O cálculo do PMV no WinComf teve como dados de entrada as variáveis climáticas para cada momento de entrevista (temperatura e umidade relativa, temperatura radiante média, velocidade do vento e pressão atmosférica), o nível de isolamento da vestimenta em clo respectivo, para a taxa metabólica fixa de 2,8 met. Para o PMV, a correlação entre os resultados encontrados e a

18 Krüger, E. L.; Drach, P. R. C.; Emmanuel, R.; Corbella, O. D. 
média das respostas de sensação térmica foi inesperadamente significativa (Figura 8), uma vez que tal índice foi desenvolvido para condições internas climatizadas. Há discrepâncias nos valores obtidos (os valores em PMV são consistentemente inferiores que a sensação térmica real, mesmo para pontos fora da curva), contudo não se deve descartar o uso do PMV como indicador da sensação térmica nas condições monitoradas, sugerindo-se como correção a aplicação da equação de regressão encontrada aos valores de PMV computados (Figura 9). Observa-se que valores calculados de PMV inferiores a -3 foram assumidos como equivalentes a -3 , de modo que ambas as escalas (sensação versus voto médio predito) fossem compatíveis.

$\mathrm{O}$ índice PET vem sendo utilizado por diversos autores como indicador das condições de conforto/desconforto térmico em ambientes externos (MATZARAKIS; MAYER; IZIOMON, 1999; SVENSSON; THORSSON; LINDQVIST..., 2003; ALI-TOUDERT; MAYER, 2006; THORSSON et al., 2007), com comprovada aplicabilidade nessas condições. No horizonte brasileiro, Monteiro (2008) e, mais recentemente, Hirashima (2010), propuseram métodos de calibração distintos do índice PET para as cidades de São Paulo e Belo Horizonte. Uma vez que o índice PET foi originalmente desenvolvido para ambientes externos, permitindo a leigos comparar de forma integrada os múltiplos efeitos de condições externas complexas no ambiente externo a condições térmicas equivalentes em um ambiente interno de referência (HÖPPE, 1999), a expectativa era que os resultados obtidos em termos de sensação térmica real fossem bastante próximos aos valores calculados na escala PET. Os valores em PET foram calculados para uma pessoa padrão ${ }^{5}$ (homem ou mulher, conforme o caso), adotando-se como dados de entrada as variáveis climáticas para cada momento de entrevista (temperatura e umidade relativa, temperatura radiante média e velocidade do vento), com o respectivo nível de isolamento da vestimenta em clo, para a taxa metabólica fixa de 2,8 met. As médias obtidas para cada grupo de pessoas cuja faixa de resultados em termos da escala PET não ultrapasse $1{ }^{\circ} \mathrm{C}$ resultaram em forte correlação (Figura 10). Tais resultados reforçam a importância e aplicabilidade do índice PET para as condições monitoradas em Glasgow.

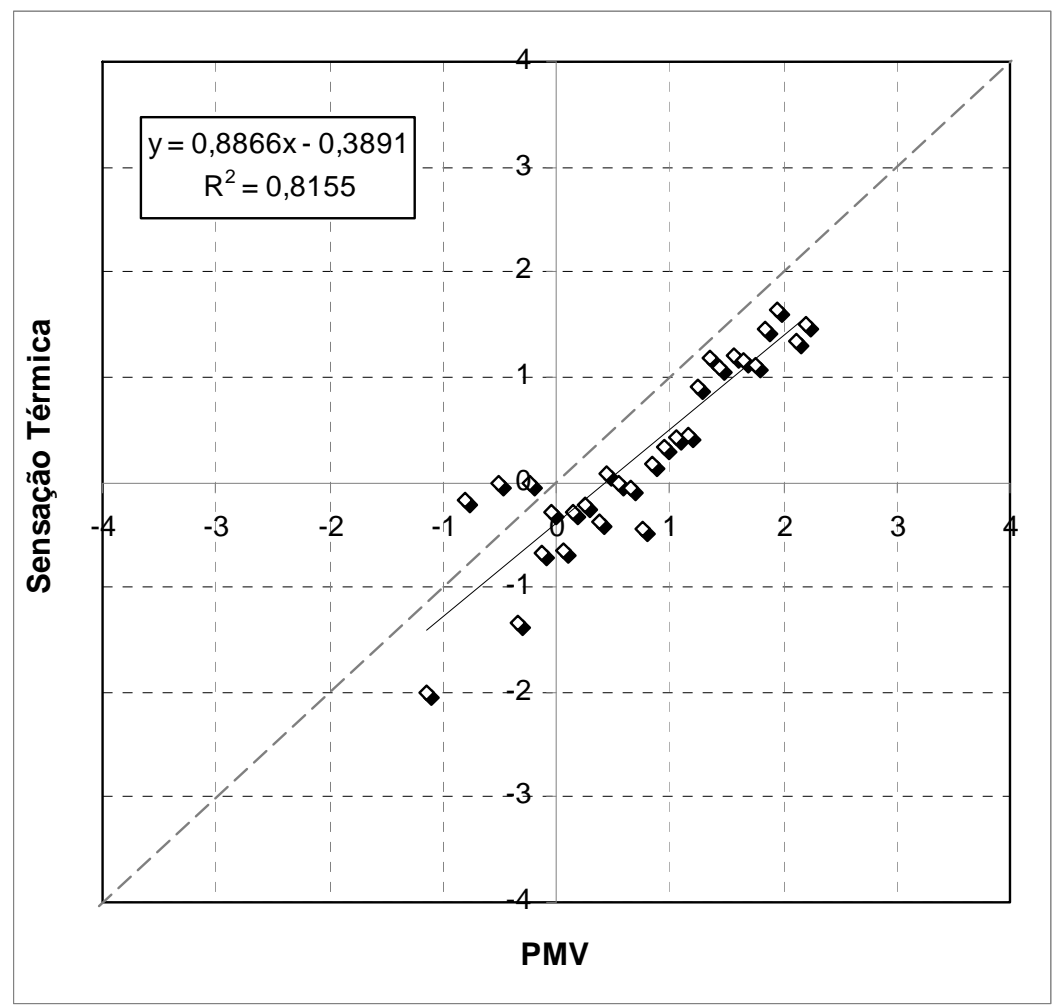

Figura 8 - Sensação térmica média versus PMV (valores agrupados por faixas de 1 décimo de gradação PMV) ${ }^{5}$

\footnotetext{
${ }^{5}$ Pela ISO 8996 (INTERNATIONAL..., 2004), o homem padrão corresponde a um indivíduo de 30 anos de idade, pesando $70 \mathrm{~kg}$ e com $1,75 \mathrm{~m}$ de altura; a mulher padrão tem 30 anos, $60 \mathrm{~kg}$ e 1,70 m.
} 


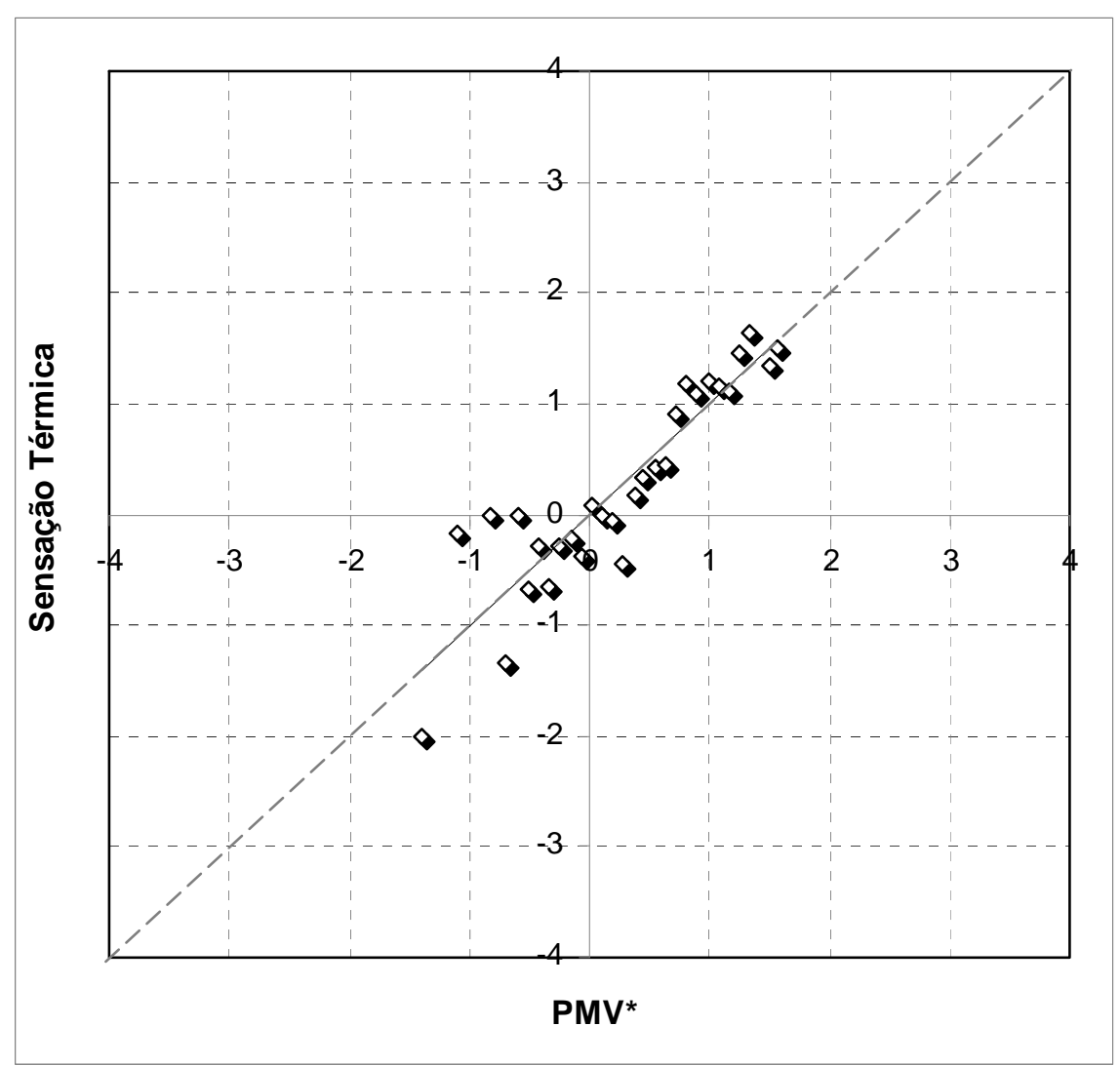

Figura 9 - Sensação térmica média versus PMV* (valores agrupados por faixas de 1 décimo de gradação PMV)

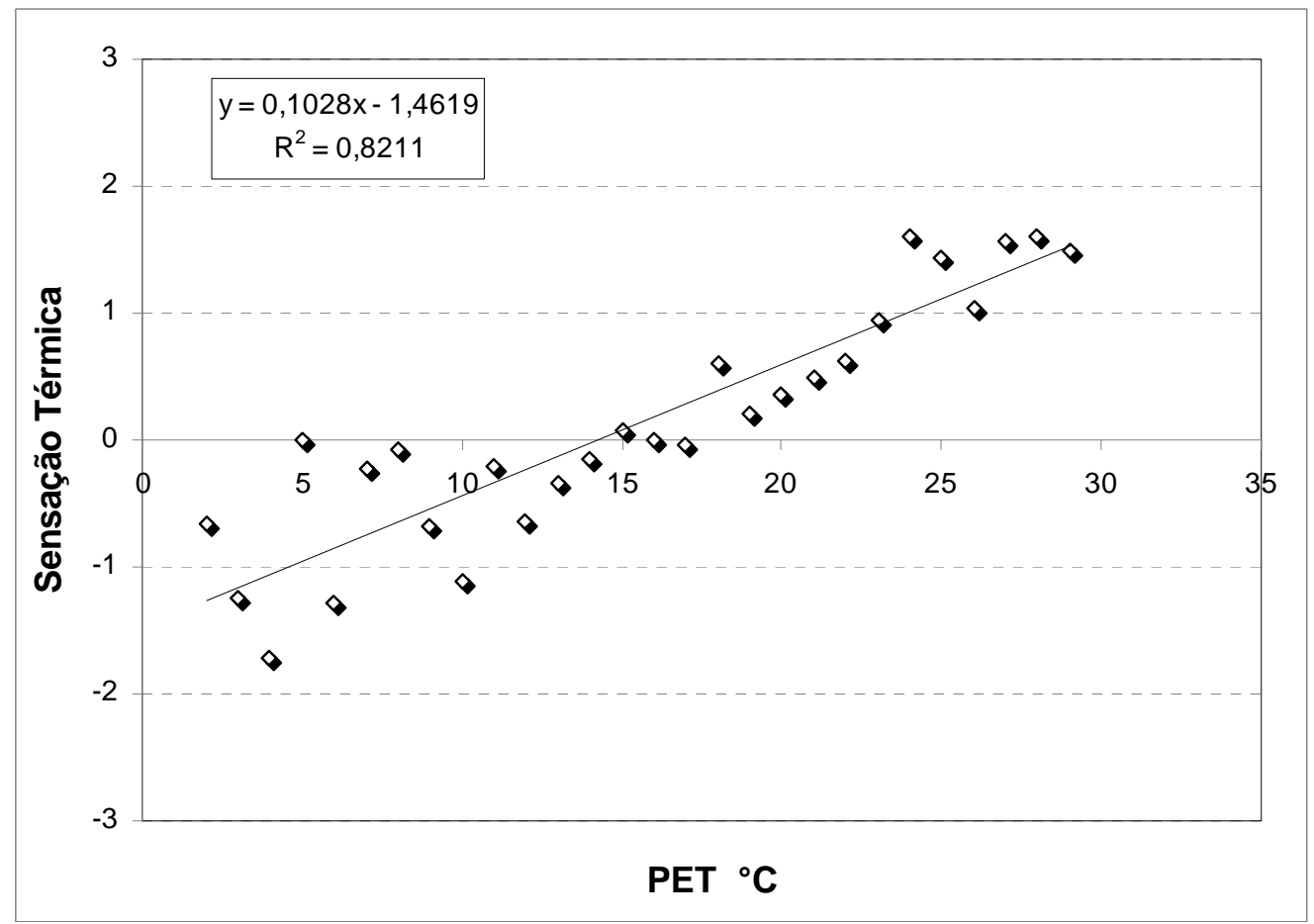

Figura 10 - Sensação térmica média versus valores encontrados na escala PET (valores agrupados por 1 grau na escala PET)

20 Krüger, E. L.; Drach, P. R. C.; Emmanuel, R.; Corbella, O. D. 
Para o índice PET, a equação de regressão para a obtenção da sensação térmica estimada a partir de valores na escala PET é dada abaixo (Eq. 4). Substituindo $\mathrm{ST}=0$, a temperatura neutra em PET é de $14,2^{\circ} \mathrm{C}$.

$\mathrm{ST}=0,1028 * \mathrm{PET}-1,4619$

Eq. 4

\section{Avaliação do efeito de variáveis climáticas na sensação de conforto}

Para esta avaliação, utilizou-se procedimento adotado por Givoni et al. (2003), com a equação de regressão múltipla para a sensação térmica (Eq. 2). Variações nas condições climáticas de irradiância solar global e velocidade do vento podem ser avaliadas quanto ao efeito equivalente na temperatura do ar na equação de regressão, a partir dos coeficientes encontrados na equação para cada variável. Desse modo, verifica-se que, para uma queda de $1{ }^{\circ} \mathrm{C}$ na temperatura do ar, um aumento na velocidade do ar de 0,19248/0,19616 $\mathrm{m} / \mathrm{s}$, ou seja, aproximadamente $1 \mathrm{~m} / \mathrm{s}$, seria necessário. De forma semelhante, a redução de 1 ${ }^{\circ} \mathrm{C}$ na temperatura do ar corresponde à redução em irradiância solar global de 0,19248/0,0005 W/m², ou seja, $385 \mathrm{~W} / \mathrm{m}^{2}$. Dado que a Eq. 2 obteve coeficiente de correlação relativamente baixo, as quantidades apresentadas (v e Ig) não devem ser entendidas como valores absolutos, mas apenas como indicadores da importância relativa de cada variável.

\section{Discussão}

As diferenças de gênero encontradas quanto à sensação térmica de cada grupo assemelham-se a resultados encontrados por Parsons (2002) em estudo em ambiente controlado, onde se variava a temperatura do ar enquanto a umidade do ar era mantida constante, ambiente sem fontes de calor. Parsons observou que, entre homens e mulheres vestidos de forma idêntica e expostos a condições variadas em sessões de $3 \mathrm{~h}$ de duração, as mulheres eram mais sensíveis a temperaturas mais baixas, sentindo mais frio que os homens (a $18,5{ }^{\circ} \mathrm{C}$, o voto de sensação térmica na escala de 7 pontos era de -1 para homens e de -2 para mulheres), corroborando os resultados encontrados na presente pesquisa. De modo semelhante aos achados de Parsons, os resultados mostraram que, enquanto as mulheres são mais sensíveis ao frio, para condições mais quentes, os votos de homens e mulheres tendem a igualar-se.

Quanto a diferenças na sensação térmica por faixa etária, os resultados mostraram que o grupo mais idoso (acima de 64 anos) é mais sensível tanto ao frio quanto ao calor. O grupo mais jovem (abaixo de 25 anos) apresentou sensação térmica coincidente com a de adultos. Uma análise mais cuidadosa dos dados mostrou que a resposta de homens e mulheres nessa faixa etária foi bastante diferenciada, havendo aí certa dispersão dos dados. Porém, considerando a diferença encontrada entre adultos e idosos, os resultados indicam haver uma tendência de pessoas mais velhas serem mais sensíveis ao frio e ao calor. Alterações na taxa metabólica em razão do aumento da idade mostram resultados contraditórios (RAVUSSIN; BOGARDUS, 1989). Taylor, Allsopp e Parkes (1995) verificaram em estudos em ambiente controlado que, em situação de frio, pessoas idosas (média de idade de 67 anos) tendem a sentir mais frio que pessoas mais jovens (média de idade 23 anos); entretanto, em situação de calor, idosos tenderam a sentir-se mais confortáveis que pessoas mais jovens. Estudo realizado por Collins, ExtonSmith e Doré (1981), porém, mostra a tendência de idosos para a hipotermia, com perda gradual da percepção térmica no decorrer dos anos de vida.

A análise dos dados quanto aos níveis de massa corporal indicou que o grupo obeso, com IMC mais elevado, apresenta acréscimo na sensação térmica tanto para frio como para calor. Para pessoas com IMC mais baixo, a amostra sugere que o mesmo efeito ocorreria para indivíduos abaixo do peso, porém há de observar-se que apenas 3,5\% da amostra é composta de tais indivíduos. Agrupando-se a amostra em duas classes apenas (normal e acima do peso+obesos), para a situação de conforto $\mathrm{ST}=0$, a diferença na sensação térmica é de dois décimos entre ambas as classes, positivamente para a classe com IMC $>25$ $\mathrm{kg} / \mathrm{m}^{2}$.

Tais resultados corroboram o fato de que pessoas com massa corporal mais elevada possuem taxa metabólica mais alta. De fato, a produção de calor metabólico basal pode ser estimada com base na altura e no peso, levando ainda em consideração o sexo do indivíduo (ZHANG et al., 2001). Uma forma de estimar-se a taxa de metabolismo basal a partir de diferenças individuais é dada, por exemplo, segundo as equações de Allen et al. (1956), para diferenças de sexo no cálculo da gordura do corpo (body fat), e de Mifflin et al. (1990), para o cálculo da taxa metabólica basal. A partir de um conjunto de equações, pode-se estimar a taxa metabólica (responsável pela produção de calor) para tais atributos individuais, sexo, peso e altura: homens apresentam taxa metabólica mais alta que mulheres, pessoas com maior massa corporal apresentam, em geral, taxa metabólica mais alta do que aquelas com massa corporal mais baixa. $\mathrm{Na}$ amostra obtida, nota-se uma variação percentual em massa corporal de $69 \%$ para homens 
e de $65 \%$ para mulheres, enquanto a variação percentual na taxa de metabolismo basal foi de $45 \%$ e de $38 \%$ respectivamente.

A comparação da sensação térmica declarada pelos entrevistados envolvendo o agrupamento de variáveis por gradações sugere que os índices THSW (meteorológico) e PET (de conforto) são os que mais se aproximam das respostas dos entrevistados. O primeiro índice, THSW, é aplicável a $81 \%$ dos dados, tendo sido encontradas 20 gradações na escala THSW; o segundo índice, PET, foi aplicado a $100 \%$ dos dados, e o número de gradações encontrado foi de 28. Para o PMV, foram aplicadas 35 gradações, correspondentes à variação de 1 décimo de PMV. De forma a uniformizar a comparação entre os índices, aplicou-se o mesmo número de gradações do PMV aos outros dois índices. A Figura 11 mostra as diferenças encontradas entre voto de sensação térmica agrupado para as 35 categorias nos três índices térmicos e os valores calculados a partir da equação de regressão resultante em cada caso.

Observa-se que há boa concordância dos dados em faixas mais altas na escala de THSW (acima de 15 ${ }^{\circ} \mathrm{C}$ na escala THSW), uma vez que condições mais frias correspondem a situações nas quais as pessoas utilizam vestimentas com isolamento térmico mais elevado, as quais não são levadas em consideração no cálculo desse índice. Já para o índice PET, as menores discrepâncias (com R2 de
0,88 e erro absoluto médio encontrado de 0,2 na escala de sensação térmica) foram observadas na faixa de 9,5-28,2 ${ }^{\circ} \mathrm{C}$ (escala PET). Tal faixa, segundo Matzarakis, Mayer e Iziomon (1999), corresponde a variações em níveis de estresse térmico de "estresse moderado ao frio" a "leve estresse ao calor". Sugere-se a não utilização do índice PET para condições mais frias (PET $\leq 9,4$ ${ }^{\circ} \mathrm{C}$ ), para o caso de Glasgow. Para o agrupamento de valores em PET em 35 categorias (gradação de $0,85^{\circ} \mathrm{C}$ na escala PET), a equação de regressão para obtenção da sensação térmica estimada a partir de valores na escala PET é dada pela Eq. 5 . Substituindo $\mathrm{ST}=0$, a temperatura neutra em PET é de $13,8^{\circ} \mathrm{C}$.

$\mathrm{ST}=0,1083 * \mathrm{PET}-1,4995$

Eq. 5

A aplicação do índice PMV aos dados climáticos monitorados, levando em conta o fator vestimenta para uma taxa metabólica constante, mostrou boa correspondência com os valores agrupados para cada décimo de PMV. A diferença absoluta máxima encontrada entre valores em PMV* (ajustado) foi de 0,93 na escala térmica (com média de 0,3). Uma observação sobre o índice PMV: a alta correlação entre valores em PMV e sensação térmica agrupada pode estar relacionada à baixa variabilidade climática de Glasgow (baixa flutuação diária e sazonal), porém, uma vez que tal índice foi desenvolvido para ambientes internos, não é sugerida sua utilização neste caso.

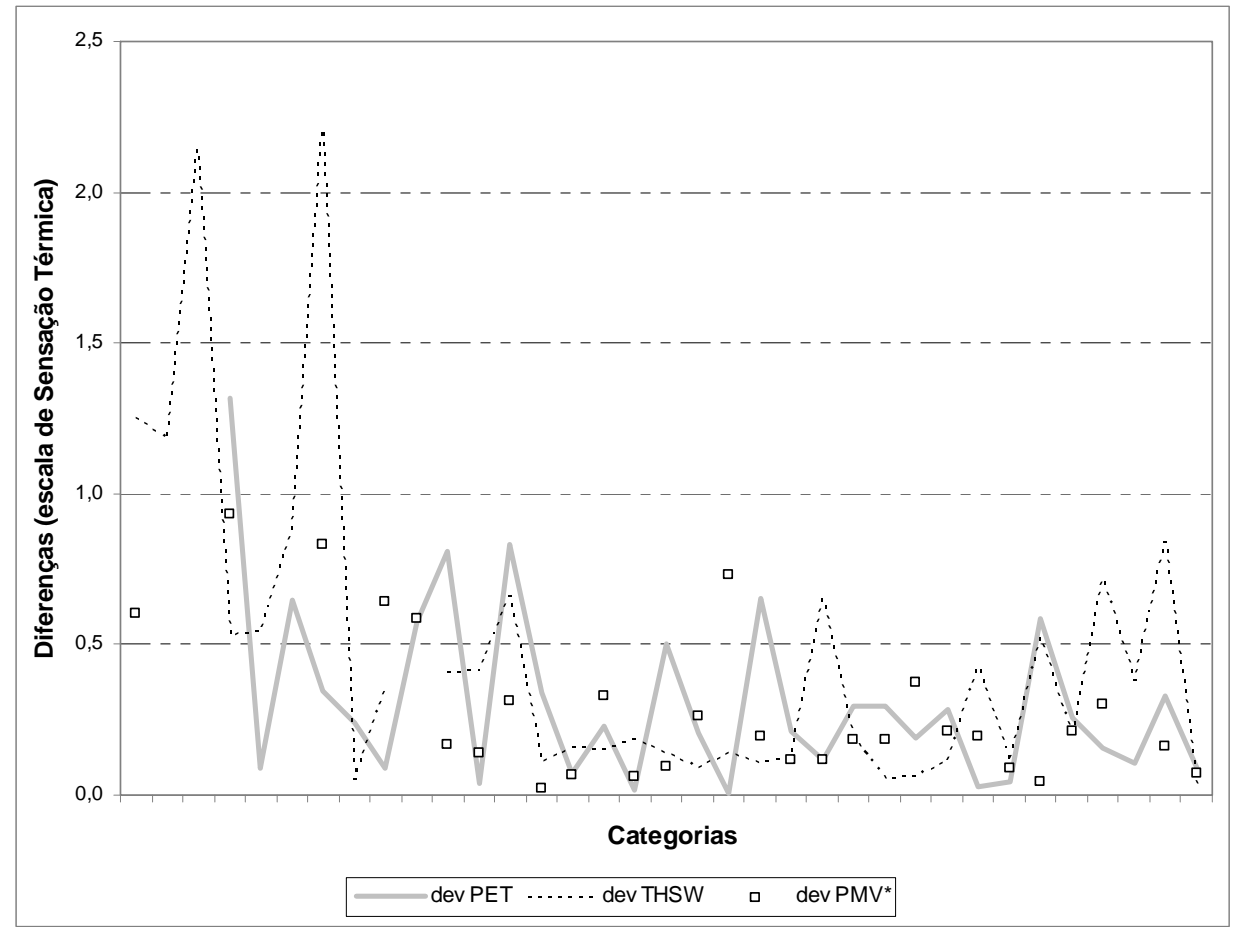

Figura 11 - Diferenças encontradas em votos de sensação térmica média versus valores preditos pelos três índices (valores agrupados em 35 gradações) 
Quanto ao efeito isolado das variáveis climáticas (velocidade do ar e irradiância solar global) na sensação térmica segundo a equação de regressão apresentada na Equação 2, pode-se estimar a média de respostas para a variação de cada variável no período completo de medição. Sabendo-se que a velocidade do vento média para cada dia de monitoramento variou de $0,2 \mathrm{~m} / \mathrm{s}$ (julho) a $1,2 \mathrm{~m} / \mathrm{s}$ (maio), as variações na sensação térmica e na temperatura do ar para tal faixa equivalem a 0,29 na escala de 7 pontos e a $1,5^{\circ} \mathrm{C}$ respectivamente. Para a irradiância solar global média/dia, cuja variação foi de $130 \mathrm{~W} / \mathrm{m} 2$ (maio) a $680 \mathrm{~W} / \mathrm{m} 2$ (julho), as variações relativas na sensação térmica e na temperatura do ar foram de $0,27{ }^{\circ} \mathrm{C}$ e $1,4{ }^{\circ} \mathrm{C}$. Tais observações mostram que ambas as variáveis têm participação semelhante na sensação térmica.

\section{Considerações finais}

Os resultados obtidos fornecem elementos para a definição preliminar de índices térmicos e faixas de utilização a partir de dados monitorados e levantamentos de conforto em espaços abertos junto à população local. A análise dos dados a partir da equação de regressão múltipla apresentada na seção 5 mostrou consistência dos resultados encontrados perante a literatura especializada. O intuito, ao utilizar-se de tal equação, não foi o de propor um índice de sensação térmico específico para a situação estudada, pois já existe um bom número de índices de conforto/sensação térmica com potenciais variados de aplicação em espaços abertos, os quais podem ser ajustados ou calibrados à realidade local (MONTEIRO, 2008). A equação desenvolvida foi adotada apenas para analisarem-se diferenças relativas entre grupos de variáveis, conforme mostrado em Análise de grupos.

A comparação dos votos de sensação térmica com os resultados calculados dos índices térmicos avaliados, de forma agrupada, sugere caminhos para futuras investigações, como a definição de faixas de conforto/desconforto para as escalas THSW e PET, e a continuidade dos estudos em espaços abertos sob condições mais frias, uma vez que a maior concentração de dados ocorreu nos períodos de primavera e verão.

A partir dos resultados encontrados, pode-se imaginar a aplicação dos índices THSW e PET para o planejamento urbano. Ferramentas tais como o ENVI-met, que fornecem as variáveis relevantes da temperatura do ar, umidade relativa, velocidade do ar e temperatura radiante média para determinada configuração urbana, podem ser adotadas em períodos menos frios do ano, verificando-se impactos na sensação térmica estimada como complementares a estudos de ilha de calor noturna.

Quanto ao THSW, índice térmico calculado automaticamente pelo software de leitura de dados da estação Davis, os resultados sugerem ser possível sua utilização para a estimativa das condições de conforto externo para valores calculados superiores a $12{ }^{\circ} \mathrm{C}$ (escala THSW). A partir de tal constatação, pode-se sugerir que estações já implantadas de mesma fabricação, muitas delas disponíveis on-line em redes de dados climáticos como o Weather Underground (WEATHER..., 2011), forneçam o valor de THSW para que se obtenham informações mais próximas à sensação térmica humana em localidades diversas. Da rede de estações Weather Underground mais próximas a Glasgow, duas delas (em Neilston e em East Kilbride) são estações Vantage Pro, da Davis. Além disso, dentro do escopo do presente projeto, foi instalada uma estação meteorológica no campus da Glasgow Caledonian University, Vantage Pro2, cujos dados em termos de THSW podem agora ser mais bem interpretados a partir dos resultados encontrados.

A principal contribuição da pesquisa é metodológica, porém os resultados fornecem elementos de comparação para respostas térmicas humanas (sensação e preferência) em regiões brasileiras subtropicais, mais especificamente, segundo a classificação de Koeppen-Geiger, para locais de clima oceânico do tipo Cf.

\section{Referências}

ALI-TOUDERT, F.; MAYER, H. Numerical Study on the Effects of Aspect Ratio and Orientation of an Urban Street Canyon on Outdoor Thermal Comfort in Hot and Dry Climate.

Building and Environment, v. 41, n. 2, p. 94-108, 2006.

ALLEN, T. H. et al. Prediction of Blood Volume and Adiposity in Man from Body Weight and Cube of Height. Metabolism, v. 5, p. 328-345, 1956.

\section{AMERICAN SOCIETY OF HEATING, REFRIGERATING AND AIR-CONDITIONING} ENGINEERS. Standard 55: thermal environmental conditions for human occupancy (ANSI Approved), 2004.

ASSOCIATION OF GERMAN ENGINEERS. VDI: methods for the human-biometeorological assessment of climate and air hygiene for urban and regional planning. Part I: climate, VDI guideline 3787. Part 2: Beuthen. Berlin, 1998. 
BRUSE, M. et al. ENVI-met. Version 3.1 BETA V. 2009. Disponível em: $<$ http://www.envimet.com>. Acesso em: 14 jul. 2011.

COLLINS, K. J.; EXTON-SMITH, A. N.; DORÉ, C. Urban Hypothermia: preferred temperature and thermal perception in old age. British Medical Journal, v. 282, p. 175-177, jan. 1981.

DE DEAR, R. J.; FOUNTAIN, M. E. Field Experiments on Occupant Comfort and Office Thermal Environments in a Hot-Humid Climate. ASHRAE Transactions, v. 100, n. 2, p. 457-474, 1994.

EMMANUEL, R. An Urban Approach to ClimateSensitive Design. London; New York: Spon Press, 2005.

ERELL, E.; PEARLMUTTER, D.;

WILLIAMSON, T. Designing the Spaces Between Buildings. London: Earthscan, 2011.

FOUNTAIN, M. E.; HUIZENGA, C. A Thermal Sensation Prediction Tool For Use by the Profession. ASHRAE Transactions, v. 103, n. 2, p. 130-136, 1997.

GIVONI, B. Climate Considerations in Building and Urban Design. Nova Iorque: Van Nostrand Reinhold, 1998.

GIVONI, B. et al. Outdoor Comfort Research Issues. Energy and Buildings, v. 35, n. 1, p. 7786, 2003.

HAN, S.; MUN, S.; HUH, J. Changes of the Micro-Climate and Building Cooling Load Due to the Green Effect of a Restored Stream in Seoul, Korea. In: INTERNATIONAL BUILDING PERFORMANCE SIMULATION ASSOCIATION CONFERENCE AND EXHIBITION, 10 ${ }^{\mathrm{TH}}$, Beijing, China, 2007. Proceedings... Beijing, China: IBPSA, 2007.

HIRASHIMA, S. Q. S. Calibração do Índice de conforto Térmico Temperatura Fisiológica Equivalente (PET) para Espaços Abertos do Município de Belo Horizonte, MG. 225 f. Belo Horizonte, 2010. Dissertação (Mestrado Insterdisciplinar Ambiente Construído e Patrimônio Sustentável) - Universidade Federal de Minas Gerais, Belo Horizonte, 2010.

HONJO, T. Thermal Comfort in Outdoor Environment. Global Environmental Research, v. 13, p. 43-47, 2009.

HÖPPE, P. Different Aspects of Assessing Indoor and Outdoor Thermal Comfort. Energy and

Buildings, v. 34, n. 6, p. 661-665, jul. 2002.
HÖPPE, P. The Physiological Equivalent Temperature: a universal index for the biometeorological assessment of the thermal environment. International Journal of Biometeorology, v. 43, n. 2, p. 71-75, 1999.

INTERNATIONAL ORGANIZATION FOR STANDARDIZATION. ISO 10551: ergonomics of the thermal environment: assessment of the influence of the thermal environment using subjective judgment scales. Geneva, 1995.

INTERNATIONAL ORGANIZATION FOR STANDARDIZATION. ISO 7726: ergonomics of the thermal environment: instruments for measuring physical quantities. Geneva. 1998.

INTERNATIONAL ORGANIZATION FOR STANDARDIZATION. ISO 7730: ergonomics of the thermal environment: analytical determination and interpretation of thermal comfort using calculation of the PMV and PPD indices and local thermal comfort criteria. Geneva. 2005.

INTERNATIONAL ORGANIZATION FOR STANDARDIZATION. ISO 8996: ergonomics of the thermal environment: determination of metabolic rate. Geneva. 2004.

\section{INTERNATIONAL ORGANIZATION FOR}

STANDARDIZATION. ISO 9920: ergonomics of the thermal environment: estimation of the thermal insulation and evaporative resistance of a clothing ensemble. Geneva, 2007.

JOHANSSON, E. Urban Design and Outdoor Thermal Comfort in Warm Climates. 2006. PhD Thesis (Housing Development and Management) - Lund University, Lund, Sweden, 2006.

KRÜGER, E.; GIVONI, B.; ROSSI, F. Outdoor Comfort Study in Curitiba, Brazil: effects of gender, body weight and age on the thermal preference. In: ADAPTING TO CHANGE: NEW THINKING ON COMFORT, Windsor, 2010. Proceedings... London: Network for Comfort and Energy Use in Buildings, 2010. v. 1, p. 1-12.

MATZARAKIS, A.; MAYER, H.; IZIOMON, M. G. Applications of a Universal Thermal Index: physiological equivalent temperature.

International Journal of Biometeorology, v. 43, p. 76-84, 1999.

MATZARAKIS, A.; RUTZ, F. Application of the RAYMAN Model in Urban Environments.

Freiburg: Meteorological Institute, University of Freiburg, 2010.

MIFFLIN, M. D. et al. A New Predictive Equation for Resting Energy Expenditure in Healthy Individuals. American Journal of Clinical Nutrition, v. 51, p. 241-247, 1990. 
MONTEIRO, L. Modelos Preditivos de Conforto Térmico: quantificação de relações entre variáveis microclimáticas e de sensação térmica para avaliação e projeto de espaços. 378 f. São Paulo, 2008. Tese (Doutorado em Tecnologia da Arquitetura e do Urbanismo) - Escola de Engenharia Civil, Universidade do Estado de São Paulo, São Paulo, 2008.

NIKOLOPOULOU, M. RUROS: Rediscovering the Urban Realm and Open Spaces. 2004a. Disponível em: $<$ http://alpha.cres.gr/ruros/>. Acesso em: 30 jul. 2011.

\section{NIKOLOPOUlOU, M. (Org.) Designing Open}

Spaces in the Urban Environment: a bioclimatic approach. Greece: Centre for Renewable Energy Sources CRES, 2004b.

NIKOLOPOULOU, M.; STEEMERS, K. Thermal Comfort and Psychological Adaptation as a Guide for Designing Urban Spaces. Energy and

Buildings, v. 35, n. 1, p. 95-101, 2003.

OSCZEVSKI, R. J. The Basis of Wind Chill. Arctic, v. 48, n. 4, p. 372-382, 1995.

OSWALT, B. P.; RIENIETS, T. Shrinking Cities: global study. 2007. Disponível em:

$<$ http://www.shrinkingcities.com/globaler_kontext. 0.html? \&L=1>. Acesso em: 30 jun. 2011.

PARSONS, K. C. The Effects of Gender, Acclimation State, the Opportunity to Adjust Clothing and Physical Disability on Requirements for Thermal Comfort. Energy and Buildings, v. 34, n. 6, p. 593-599, 2002.

RAVUSSIN, E.; BOGARDUS, C. Relationship of Genetics, Age, and Physical Fitness to Daily Energy Expenditure and Fuel Utilization. The American Journal of Clinical Nutrition, v. 49, n. 5, p. 968-975, 1989.

SPAGNOLO, J.; DE DEAR, R. A Field Study of Thermal Comfort in Outdoor and Semi-Outdoor Environments in Subtropical Sydney, Australia. Building and Environment, v. 38, n. 5, p. 721738, 2003.
STEADMAN, R. G. A Universal Scale of Apparent Temperature. Journal of Climate and Applied Meteorology, v. 23, p. 1674-1687, 1984.

SVENSSON, M. K.; THORSSON, S.; LINDQVIST, S. A Geographical Information System Model for Creating Bioclimatic Maps: examples from a high, mid-latitude city.

International Journal of Biometeorology, v. 47, n. 2, p. 102-112, 2003.

TAYLOR, N. A. S.; ALLSOPP, N. K.; PARKES, D. G. Preferred Room Temperature of Young vs Aged Males: the influence of thermal sensation, thermal comfort, and affect. Journals of Gerontology Series A: Biological Sciences and Medical Sciences, v. 50A, n. 4, p. M216-M221, 1995.

THORSSON, S. et al. Thermal Comfort and Outdoor Activity in Japanese Urban Public Places. Environment and Behavior, v. 39, n. 2, p. 1-25, 2007.

UK MET OFFICE. Western Scotland: climate. Disponível em:

$<$ http://www.metoffice.gov.uk/climate/uk/ws/print. html>. Acesso em: 16 jun. 2011.

WEATHER UNDERGROUND. Disponível em: $<$ http://www.wunderground.com>. Acesso em: 17 ago. 2011.

WORLD HEALTH ORGANIZATION. Physical Status: the use and interpretation of anthropometry. Report of a WHO Expert Committee, WHO Technical Report Series, 1995.

ZHANG, H. et al. Considering Individual Physiological Differences in a Human Thermal Model. Journal of Thermal Biology, v. 26, p. 401-408, 2001.

\section{Agradecimentos}

Os autores agradecem às agências de fomento que patrocinaram a pesquisa $(\mathrm{CNPq}$ e $\mathrm{CAPES})$ e à School of Engineering and Built Environment/Glasgow Caledonian University, pela estrutura de apoio.

Revista Ambiente Construído

Associação Nacional de Tecnologia do Ambiente Construído

Av. Osvaldo Aranha, 99 - 3o andar, Centro

Porto Alegre - RS - Brasil

CEP 90035-190

Telefone: +55 (51) 3308-4084

Fax: +55 (51) 3308-4054

www. seer. ufrgs. br/ ambienteconstruido

E-mail: ambienteconstruido@ufrgs.br 